\title{
Maternal prepregnancy surgery and risk of neonatal abstinence syndrome in future newborns: a longitudinal cohort study
}

\author{
Nathalie Auger MD MSc, Nancy Low MD MSc, François M. Carrier MD MSc, Aimina Ayoub MSc, Thuy Mai Luu MD MSc
}

Cite as: CMAJ 2019 July 15;191:E779-86. doi: 10.1503/cmaj.181519

Visual abstract available at www.cmaj.ca/lookup/suppl/doi:10.1503/cmaj.181519/-/DC2

\begin{abstract}
BACKGROUND: Neonatal abstinence syndrome is increasingly prevalent, and may be related to opioid use disorders caused by postoperative prescriptions for pain control. We assessed the association of maternal prepregnancy surgery with risk of neonatal abstinence syndrome from opioid use disorders in future pregnancies.
\end{abstract}

METHODS: We conducted a longitudinal retrospective cohort study of 2182365 deliveries in Quebec, Canada, between 1989 and 2016. The main exposure was maternal prepregnancy surgery. The main outcome measure was neonatal abstinence syndrome in offspring. We adjusted associations for maternal comorbidity and pregnancy characteristics using logbinomial regression models.

RESULTS: The prevalence of neonatal abstinence syndrome in the cohort was 10.7 per 10000 births. Compared with no surgery, prepregnancy surgery was associated with a risk ratio (RR) of neonatal abstinence syndrome of 1.63 (95\% confidence interval $[\mathrm{Cl}]$ 1.49-1.78). Risk was greater for 3 or more prepregnancy surgeries (RR 2.34, 95\% Cl 2.07-2.63) and age $<15$ years at first surgery (1 surgery: RR $2.08,95 \% \mathrm{Cl} 1.71-2.54$; 2 or more surgeries: RR 2.79, 95\% Cl 2.32-3.37). Nearly all surgical specialties increased the risk of neonatal abstinence syndrome, but associations were strongest for cardiothoracic surgery (RR 4.45, 95\% Cl 2.876.91), neurosurgery (RR $3.00,95 \% \mathrm{Cl}$ 1.56-5.77) and urologic surgery (RR 3.03, $95 \% \mathrm{Cl} 2.16-4.26)$.

INTERPRETATION: Prepregnancy surgery is associated with the risk of neonatal abstinence syndrome in future pregnancies. Prescription opioids for postsurgical pain may result in opioid use disorders during future pregnancies, inadvertently increasing the risk of neonatal abstinence syndrome in offspring.

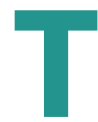

he opioid epidemic has led to an alarming increase in the number of infants with neonatal abstinence syndrome in the United States and Canada. ${ }^{1-3}$ Between 2009 and 2013, the incidence of neonatal abstinence syndrome doubled from 3.6 to 7.3 per 1000 births in the US alone. ${ }^{2}$ Neonatal abstinence syndrome is a withdrawal syndrome caused by sudden interruption of intrauterine drug exposure at birth and occurs in $55 \%-94 \%$ of infants exposed to opioids prenatally. ${ }^{4-6}$ Symptoms include fever, respiratory complications, weight loss and seizures, and affected infants frequently require admission to the intensive care unit. ${ }^{4-6}$ Complications are not limited to the neonatal period, and include injury, infection, mental and behavioural disorders and ophthalmologic disorders. ${ }^{7,8}$ Many of these complications could be avoided by preventing intrauterine exposure to opioids, which is challenging as the factors leading to chronic opioid use in women have not been fully elucidated.

Many women are first introduced to opioids after surgery through prescriptions for postoperative pain control, ${ }^{9-12}$ but the potential link with neonatal abstinence syndrome in future pregnancies has never been assessed. Opioids are commonly prescribed for postsurgical pain ${ }^{9-12}$ and predispose young surgical patients to prolonged opioid use. ${ }^{11}$ Nearly $5 \%$ of young opioidnaive patients continue to use opioids several months after surgery. ${ }^{11}$ Owing to the high frequency of surgical procedures at young ages, ${ }^{11}$ women who undergo surgery may be more vulnerable to prolonged opioid use during their reproductive years.

The possibility that opioid use after surgery can be substantial enough to persist in future pregnancies has not been considered. We sought to determine the association of maternal prepregnancy surgery with the subsequent risk of neonatal abstinence syndrome in infants.

\section{Methods}

\section{Study design and population}

We performed a retrospective cohort study of 2182365 births between 1989 and 2016 in Quebec, Canada. We used hospital data compiled in the Maintenance and Use of Data for the Study 
of Hospital Clientele registry to identify the births. ${ }^{13}$ The data comprise discharge abstracts from all hospital admissions in Quebec, including pregnant women paired with their newborns, and are coded by trained personnel and validated using strict criteria. ${ }^{13}$ As $99 \%$ of infants are born in hospital in Quebec, the cohort is representative of most pregnancies in the population.

We used scrambled health insurance numbers to follow the women back in time for admissions to hospital for prepregnancy surgery. Women with invalid health insurance numbers were excluded, as we could not track them over time. We did not include women with a documented substance use disorder at the time of surgery, to ensure the surgery preceded the use of opioids. We also excluded stillbirths, as fetal death precludes a diagnosis of neonatal abstinence syndrome (Appendix 1, available at www.cmaj.ca/lookup/suppl/doi:10.1503/cmaj.181519/-/DC1).

\section{Exposure}

The main exposure measure was prepregnancy surgery. In Quebec, all major surgeries are performed in hospital and were available in the data set. We captured surgeries by identifying women who required general, regional or local anesthesia at any time before conception or during pregnancy before delivery, as far back as Apr. 1, 1989. We could identify up to 20 surgeries during each hospital admission, but not minor surgeries performed in ambulatory clinics.

We distinguished surgeries under general versus local or regional anesthesia, as general anesthesia may be a marker of more serious and complex surgery. We measured the number of surgeries, age at surgery and time between surgery and delivery as categorical variables, including women without surgery in a separate category. Younger age at surgery is an indicator of earlier exposure to opioids, which research suggests may be associated with a greater risk of opioid abuse. ${ }^{14,15}$ Time between surgery and delivery captures more women with opioid exposures at younger ages who may have multiple surgeries, or more time to develop opioid tolerance and hyperalgesia requiring higher opioid doses. ${ }^{16}$

We used the surgical specialty to classify interventions, including general surgery, cardiovascular or thoracic surgery, neurosurgery, orthopedic, urologic, obstetric or gynecologic, plastic or dermatologic surgery, ophthalmology, otorhinolaryngology, oral and maxillofacial or dental, and other surgery. We did so because complex and invasive surgeries may require more opioids for pain control. ${ }^{17}$

\section{Primary outcome}

The outcome was neonatal abstinence syndrome. We used codes from the 9th and 10th Revisions of the International Classification of Diseases to identify infants given a diagnosis of neonatal abstinence syndrome at birth or during a postnatal readmission (Appendix 2, available at www.cmaj.ca/lookup/suppl/doi:10.1503 /cmaj.181519/-/DC1). We could not confirm the validity of diagnostic codes for neonatal abstinence syndrome, but studies report high sensitivity and specificity for related outcomes. ${ }^{18,19} \mathrm{We}$ could not determine the underlying drug, but most cases are caused by opioids., ${ }^{5,6}$

\section{Covariates}

We accounted for confounders that may affect the association between prepregnancy surgery and neonatal outcomes. We identified pain comorbidities that were present at or before the admission to hospital for surgery, focusing on disorders that could lead to opioid use well before the index surgery (Appendix 2). Comorbidities included cancer, neuropathy, migraine and other headaches, dorsopathy, musculoskeletal disorders, arthropathy, urolithiasis, endometriosis and other inflammatory reproductive disorders, inflammatory bowel disease, sickle cell disease, and other chronic pain syndromes, examined individually and as a composite score (yes or no). ${ }^{20}$ We did not include acute pain problems that triggered the surgery, such as trauma or burns. For women who had never had surgery, we identified pain comorbidities during pregnancy or previous admissions to hospital.

Because mental illness is associated with chronic opioid use, ${ }^{20,21}$ we accounted for women with depression, bipolar disorder, schizophrenia, anxiety disorder, stress-related disorder, personality disorder and suicide attempt, examined individually and as a composite score (yes or no; see Appendix 2). We accounted for maternal age at delivery $(<25,25-34, \geq 35 \mathrm{yr})$, parity $(0,1, \geq 2$ previous deliveries), socioeconomic deprivation defined as residence in the most disadvantaged fifth of neighbourhoods based on income, employment and education (disadvantaged, not disadvantaged or unspecified), ${ }^{22}$ place of residence (rural, urban or unspecified), and time period at delivery (1989-2005 or 2006-2016).

\section{Statistical analysis}

We determined the prevalence of neonatal abstinence syndrome per 10000 infants. In primary analyses, we used log-binomial regression models to calculate risk ratios (RRs) and 95\% confidence intervals (Cls) for the association of maternal prepregnancy surgery with the future risk of neonatal abstinence syndrome, rather than odds ratios. ${ }^{23}$ Regression models were adjusted for maternal pain comorbidity, mental illness, age at delivery, parity, socioeconomic deprivation, place of residence and time period at birth. We used generalized estimating equations to account for clustering of births within women. ${ }^{24}$

In secondary analyses, we evaluated the association of the total number of prepregnancy surgeries, and general versus local or regional anesthesia, with the risk of neonatal abstinence syndrome. We also analyzed age at surgery and time between surgery and delivery, accounting for whether women had 1 or multiple admissions to hospital for surgery. For women who had multiple admissions for surgery, we examined both the first and last procedure. In subgroup analyses, we explored the associations after excluding women with pain comorbidities to maximize the likelihood that the prepregnancy surgery was the first opioid exposure. We also determined if the risk varied by type of surgery.

In sensitivity analyses, we excluded infants born before 2000 , to ensure that we had at least a decade of follow-up on maternal prepregnancy surgeries. We compared restricted cubic spline models expressing time from first surgery and age at first surgery as continuous variables with the categorical models used in the main analysis to confirm that no problems existed with nonlinearity. 
We tested models adjusted for each pain comorbidity and mental illness separately using inverse propensity score weighting, which allowed us to account for more covariates. ${ }^{25}$ All analyses were performed in SAS v 9.4 (SAS Institute Inc., Cary, NC). We used deidentified hospital data.

\section{Ethics approval}

We received an ethics waiver from the University of Montreal Hospital Centre.

\section{Results}

Among 2182365 neonates, 2346 had neonatal abstinence syndrome, for an overall prevalence of 10.7 per 10000 infants (95\% Cl 10.3-11.2) (Table 1). Among infants with neonatal abstinence syndrome, 1052 had mothers with prepregnancy surgery (14.9 per 10000), and 1294 had mothers with no surgery (8.8 per 10000$)$.

Prepregnancy surgery was associated with the future risk of neonatal abstinence syndrome (Table 2). In adjusted models, women who underwent surgery had 1.63 times the risk of neonatal abstinence syndrome in a future pregnancy $(95 \% \mathrm{Cl} 1.49-$ $1.78)$, compared with no surgery. The risk was significantly greater for women with 3 or more procedures (RR $2.34,95 \% \mathrm{Cl}$ 2.07-2.63). Risks were present regardless of the type of anesthesia, although the association was slightly stronger for general (RR $1.69,95 \% \mathrm{Cl} 1.54-1.85)$ than local or regional anesthesia (RR 1.32, 95\% Cl 1.09-1.60).

Younger age at first surgery was associated with the risk of neonatal abstinence syndrome regardless of the total number of

Table 1: Prevalence of neonatal abstinence syndrome in newborns according to maternal characteristics

\section{Characteristics}

No. of infants

Prepregnancy surgery

Yes

No

705966

1476399

Maternal pain comorbidity

Yes

No

148769

2033596

Maternal mental illness $†$

Yes

No

35666

2146699

Maternal age at delivery, yr

$<25$

455057

1429257

298051

$\geq 35$

Parity

0

1

$\geq 2$

Socioeconomic deprivation

Yes

No

1638542

419754

1704423

1351672

830693

2182365

Total
No. of infants with neonatal abstinence syndrome

1052

1294

265

2081

249

2097

801

1290

255

1282

581

483

805

1431

400

1925

1417

929

2346
Prevalence per 10000 $(95 \% \mathrm{Cl})$

$14.9(14.0-15.8)$

$8.8(8.3-9.2)$

$17.8(15.7-20.0)$

$10.2(9.8-10.7)$

$69.8(61.2-78.5)$

$9.8(9.4-10.2)$

17.6 (16.4-18.8)

$9.0(8.5-9.5)$

$8.6(7.5-9.6)$

$10.4(9.8-11.0)$

$8.3(7.7-9.0)$

$18.9(17.3-20.6)$

$18.6(17.3-19.9)$

$8.7(8.3-9.2)$

$9.5(8.6-10.5)$

$11.3(10.8-11.8)$

$10.5(9.9-11.0)$

$11.2(10.5-11.9)$

$10.7(10.3-11.2)$

Note: $\mathrm{Cl}=$ confidence interval.

*Cancer, neuropathy, migraine and other headaches, dorsopathy, musculoskeletal disorders, arthropathy, urolithiasis, reproductive disorders, inflammatory bowel disease and sickle cell disease.

†Depression, bipolar disorder, schizophrenia, anxiety disorder, stress-related disorder, personality disorder and suicide attempt. 
Table 2: Association between maternal prepregnancy surgery and risk of neonatal abstinence syndrome in infants

\begin{tabular}{|c|c|c|c|c|c|}
\hline \multirow[b]{2}{*}{ Maternal characteristics } & \multirow[b]{2}{*}{ No. of infants } & \multirow{2}{*}{$\begin{array}{l}\text { No. of infants } \\
\text { with neonatal } \\
\text { abstinence } \\
\text { syndrome }\end{array}$} & \multirow{2}{*}{$\begin{array}{c}\text { Prevalence per } \\
10000 \\
(95 \% \mathrm{CI})\end{array}$} & \multicolumn{2}{|c|}{$\begin{array}{c}\text { Risk ratio } \\
(95 \% \mathrm{Cl})\end{array}$} \\
\hline & & & & Unadjusted & Adjusted* \\
\hline \multicolumn{6}{|l|}{ Surgery } \\
\hline Yes & 705966 & 1052 & $14.9(14.0-15.8)$ & $1.69(1.55-1.84)$ & $1.63(1.49-1.78$ \\
\hline No & 1476399 & 1294 & $8.8(8.3-9.2)$ & Referent & Referent \\
\hline \multicolumn{6}{|c|}{ Total no. of hospital admissions for surgery } \\
\hline 0 & 1476399 & 1294 & $8.8(8.3-9.2)$ & Referent & Referent \\
\hline 1 & 460060 & 549 & $11.9(10.9-12.9)$ & $1.36(1.22-1.51)$ & $1.34(1.21-1.49)$ \\
\hline 2 & 155781 & 252 & $16.2(14.2-18.2)$ & $1.82(1.58-2.10)$ & $1.77(1.53-2.05)$ \\
\hline$\geq 3$ & 90125 & 251 & $27.9(24.4-31.3)$ & $3.19(2.77-3.68)$ & $2.98(2.58-3.45)$ \\
\hline \multicolumn{6}{|l|}{ Total no. of surgeries } \\
\hline 0 & 1476399 & 1294 & $8.8(8.3-9.2)$ & Referent & Referent \\
\hline 1 & 333594 & 375 & $11.2(10.1-12.4)$ & $1.28(1.14-1.44)$ & $1.27(1.13-1.44$ \\
\hline 2 & 164901 & 235 & $14.3(12.4-16.1)$ & $1.57(1.35-1.82)$ & $1.54(1.33-1.79)$ \\
\hline$\geq 3$ & 207471 & 442 & $21.3(19.3-23.3)$ & $2.44(2.18-2.74)$ & $2.34(2.07-2.63)$ \\
\hline \multicolumn{6}{|c|}{ Type of anesthesia used for surgery } \\
\hline General & 598764 & 920 & $15.4(14.4-16.4)$ & $1.75(1.60-1.91)$ & $1.69(1.54-1.85)$ \\
\hline Local or regional only & 107202 & 132 & $12.3(10.2-14.4)$ & $1.35(1.12-1.64)$ & $1.32(1.09-1.60)$ \\
\hline No surgery & 1476399 & 1294 & $8.8(8.3-9.2)$ & Referent & Referent \\
\hline
\end{tabular}

surgeries (Table 3). Relative to no surgery, women with multiple surgeries who were younger than 15 years at their first surgery had 2.79 times the risk of neonatal abstinence syndrome $(95 \% \mathrm{Cl}$ 2.32-3.37), and women with only 1 surgery had 2.08 times the risk (95\% $\mathrm{Cl} 1.71-2.54)$. In women with multiple surgeries, associations with the last surgery did not vary significantly across age. The patterns were similar when we examined time between surgery and future pregnancy.

Essentially all types of surgery were associated with an increased risk of neonatal abstinence syndrome (Table 4). The risk was greatest for women who underwent cardiovascular or thoracic surgery (RR 4.45, 95\% Cl 2.87-6.91), neurosurgery (RR 3.00, 95\% Cl 1.56-5.77) and urologic surgery (RR 3.03, $95 \% \mathrm{Cl} 2.16-4.26)$, compared with no surgery.

In the subgroup analysis of women with no pain comorbidity ( $n=2033596$ deliveries), the association of prepregnancy surgery with the future risk of neonatal abstinence syndrome strengthened slightly (Table 5). Prepregnancy surgery in women without comorbidity was associated with 1.74 times the risk of neonatal abstinence syndrome ( $95 \% \mathrm{Cl} 1.59-1.91)$, compared with no surgery. In sensitivity analyses, excluding 928000 infants born before 2000 did not influence the results; nor did adjusting for specific pain comorbidities and mental disorders separately (Appendix 3, available at www.cmaj.ca/lookup/suppl/doi:10.1503/ cmaj.181519/-/DC1).

\section{Interpretation}

In this study of more than 2 million deliveries, maternal prepregnancy surgery was associated with 1.6 times the risk of neonatal abstinence syndrome in future offspring. Associations were stronger when there were multiple surgeries, younger age at surgery, more time between surgery and delivery, and surgeries that involved the cardiothoracic, neurosurgical or urologic specialties. The associations persisted even when we excluded women with a history of comorbidity who may have used opioids for preexisting pain. This study provides novel evidence that surgery in women may lead to opioid use substantial enough to cause neonatal abstinence syndrome in future newborns.

Postsurgical prescriptions for pain control are the initial point of exposure to opioids for many women, ${ }^{9-12}$ but the association with prolonged use into pregnancy has not been previously evaluated. Several studies show that postsurgical prescriptions increase the risk of chronic opioid use. ${ }^{11,12,26-28} \mathrm{~A}$ retrospective study of 199069 patients aged 13 to 21 years found that $4.8 \%$ of opioid-naive surgical patients received opioid refills more than 3 months after surgery, compared with $0.1 \%$ in nonsurgical patients. ${ }^{11}$ Studies of older surgical patients also report higher risks of chronic opioid use after surgery across varied procedures. ${ }^{12,26-28}$ Most studies are, however, limited to the first few months after surgery. 
Table 3: Association between age and timing of maternal prepregnancy surgery with risk of neonatal abstinence syndrome in infants*

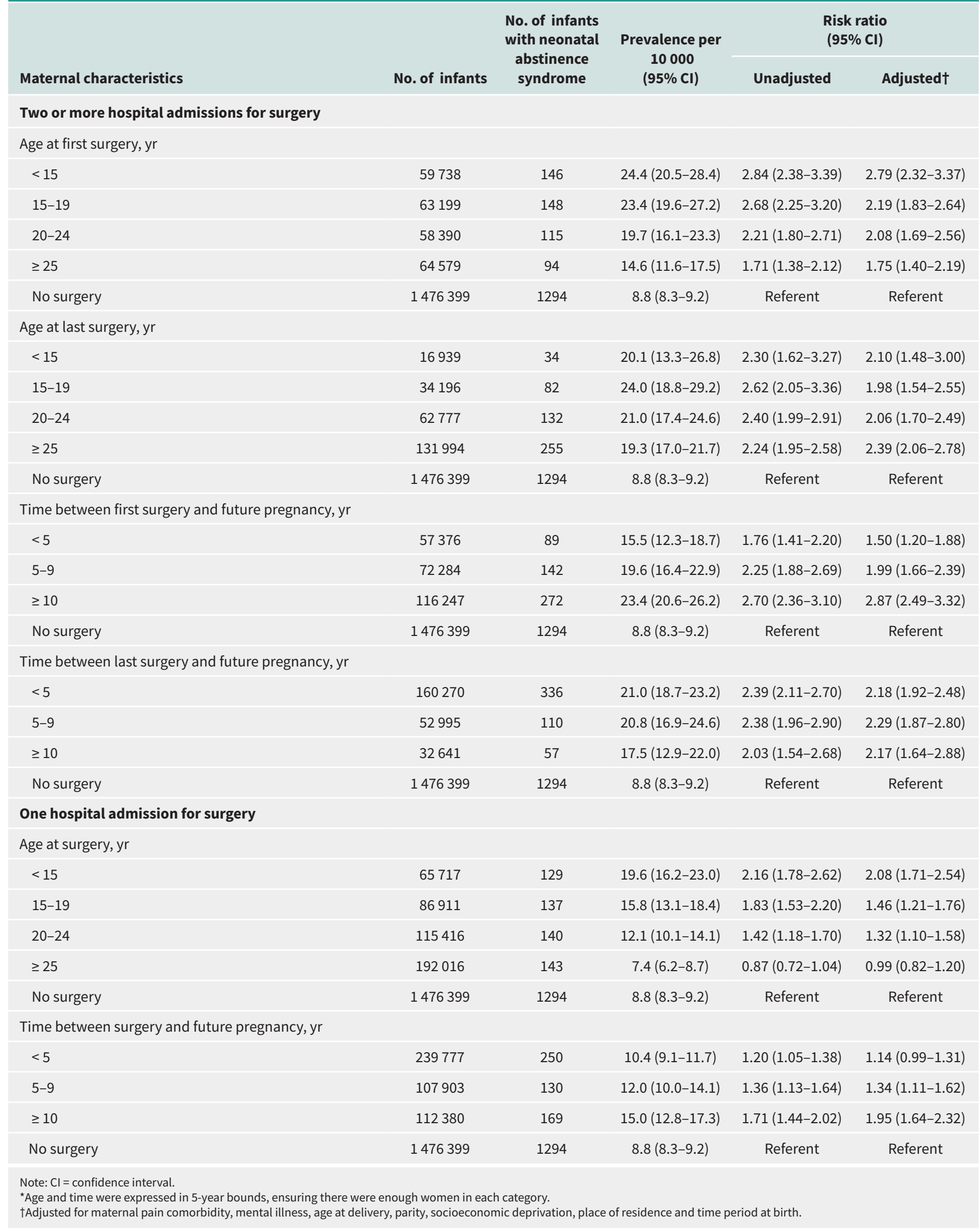


Table 4: Association between type of maternal prepregnancy surgery and risk of neonatal abstinence syndrome in infants

\begin{tabular}{|c|c|c|c|c|c|}
\hline \multirow[b]{2}{*}{ Type of surgery ${ }^{\star}$} & \multirow[b]{2}{*}{ No. of infants } & \multirow{2}{*}{$\begin{array}{l}\text { No. of infants } \\
\text { with neonatal } \\
\text { abstinence } \\
\text { syndrome }\end{array}$} & \multirow{2}{*}{$\begin{array}{c}\text { Prevalence per } \\
10000 \\
(95 \% \mathrm{Cl})\end{array}$} & \multicolumn{2}{|c|}{$\begin{array}{c}\text { Risk ratio } \\
(95 \% \mathrm{Cl})\end{array}$} \\
\hline & & & & Unadjusted & Adjusted $t$ \\
\hline General & 182550 & 298 & $16.3(14.5-18.2)$ & $1.86(1.63-2.12)$ & $1.72(1.51-1.97)$ \\
\hline Cardiovascular or thoracic & 5317 & 23 & $43.3(25.6-60.9)$ & $4.99(3.23-7.72)$ & $4.45(2.87-6.91)$ \\
\hline Neurosurgery & 3858 & 12 & $31.1(13.5-48.7)$ & $3.69(1.96-6.96)$ & $3.00(1.56-5.77)$ \\
\hline Orthopedic & 76187 & 138 & $18.1(15.1-21.1)$ & $2.10(1.75-2.53)$ & $1.98(1.60-2.46)$ \\
\hline Urologic & 12355 & 42 & $34.0(23.7-44.3)$ & $3.85(2.81-5.27)$ & $3.03(2.16-4.26)$ \\
\hline Obstetric or gynecologic & 321806 & 541 & $16.8(15.4-18.2)$ & $1.88(1.69-2.09)$ & $1.80(1.61-2.02)$ \\
\hline Plastic or dermatologic & 72001 & 130 & $18.1(15.0-21.2)$ & $2.06(1.70-2.49)$ & $2.13(1.76-2.58)$ \\
\hline Ophthalmology & 11630 & 23 & $19.8(11.7-27.9)$ & $2.26(1.43-3.57)$ & $2.44(1.54-3.86)$ \\
\hline Otorhinolaryngology & 140653 & 235 & $16.7(14.6-18.8)$ & $1.89(1.64-2.19)$ & $1.95(1.68-2.25)$ \\
\hline Oral and maxillofacial or dental & 48874 & 92 & $18.8(15.0-22.7)$ & $2.17(1.73-2.70)$ & $2.15(1.73-2.68)$ \\
\hline Other & 9062 & 16 & $17.7(9.0-26.3)$ & $1.91(1.13-3.22)$ & $1.52(0.90-2.54)$ \\
\hline No surgery & 1476399 & 1294 & $8.8(8.3-9.2)$ & Referent & Referent \\
\hline
\end{tabular}

Our findings suggest that surgery in young women may lead to opioid use that persists into future pregnancies. Associations were particularly high in women who underwent multiple surgeries. These women are at risk of receiving opioid prescriptions several times, which likely increases their chance of chronic opioid use. A strong association was also present for general anesthesia, an indicator of more complex procedures that may require higher doses and longer duration of analgesics, 2 determinants of prolonged opioid use. ${ }^{10,29}$ Furthermore, girls exposed to opioids during childhood or adolescence may not have the maturity to understand the risks associated with continued opioid use, and be more likely to develop opioid use disorders. ${ }^{14,15}$ This may explain why both younger age and time since surgery were associated with a greater risk of neonatal abstinence syndrome in this study. Longer time since surgery may also be associated with dose escalation from opioid tolerance or hyperalgesia. ${ }^{16}$

Physicians have the potential to prevent neonatal abstinence syndrome through more careful postoperative pain management of young women. Opioids are currently a cornerstone of postsurgical pain management. ${ }^{9-12}$ Nearly $80 \%$ of surgical patients have acute postoperative pain, with most reporting moderate to extreme pain. ${ }^{30}$ Acute postoperative pain can persist for months after surgery and become chronic. ${ }^{17}$ Chronic postsurgical pain affects about $10 \%$ of all surgical patients, owing to iatrogenic nerve injury or opioid-induced hyperalgesia. ${ }^{17}$ Many patients may use opioid analgesics over an extended period, increasing their chance of opioid use disorders. ${ }^{10,16,29}$ Evidence suggests that as many as $75 \%$ of heroin users begin their abuse with prescription opioids. ${ }^{31}$

Opioids continue to be overprescribed, despite calls to optimize postoperative pain control through efforts ranging from improvement of surgical guidelines to the use of multimodal techniques involving nonopioid analgesics or regional anesthesia. ${ }^{10}$ Although surgeons are faced with having to prescribe enough opioids for postsurgical pain control, studies show that the dose and duration is frequently overestimated. ${ }^{10}$ As many as $92 \%$ of patients have surplus opioids after surgery. ${ }^{10}$ Leftovers become a source for future use, ${ }^{10}$ and young women may underestimate the dangers of opioid exposure, especially during pregnancy. These women may benefit from a better description of the risk of prenatal opioid use and from closer management to identify those who need opioid maintenance therapy. Treatment with buprenorphine, which is associated with a lower risk of neonatal abstinence syndrome than methadone, ${ }^{32}$ should be considered.

\section{Limitations}

Rates of opioid prescription are relatively low in Quebec. ${ }^{33}$ In addition, the prevalence of neonatal abstinence syndrome may be underestimated in hospital data. ${ }^{34}$ Neonatal abstinence syndrome may be misdiagnosed, and the difficulty of identifying pregnant women who use opioids can further hinder diagnosis. ${ }^{4,6,34}$ These issues may all contribute to the low prevalence of neonatal abstinence syndrome in Quebec, compared with regions such as the US, where the rate is as high as 21.2 per $1000 .^{2}$ It is therefore likely that maternal prepregnancy surgery has a much larger impact on the absolute number of cases of neonatal abstinence syndrome.

We cannot rule out residual confounding from undocumented chronic pain syndromes, ethnicity and prepregnancy smoking. We analyzed the surgical specialty, but not the exact procedure. We evaluated procedures that required anesthesia, and may 
Table 5: Association between maternal prepregnancy surgery and neonatal abstinence syndrome in newborns of women with no pain comorbidity

\begin{tabular}{|c|c|c|c|c|}
\hline Maternal characteristics & No. of infants & $\begin{array}{l}\text { No. of infants } \\
\text { with neonatal } \\
\text { abstinence } \\
\text { syndrome }\end{array}$ & $\begin{array}{l}\text { Prevalence per } 10000 \\
(95 \% \mathrm{CI})\end{array}$ & $\begin{array}{l}\text { Risk ratio } \\
(95 \% \mathrm{Cl})^{\star}\end{array}$ \\
\hline \multicolumn{5}{|l|}{ Surgery } \\
\hline Yes & 607386 & 902 & $14.9(13.9-15.8)$ & $1.74(1.59-1.91)$ \\
\hline No & 1426210 & 1179 & $8.3(7.8-8.7)$ & Referent \\
\hline \multicolumn{5}{|c|}{ Total no. of hospital admissions for surgery } \\
\hline 0 & 1426210 & 1179 & $8.3(7.8-8.7)$ & Referent \\
\hline 1 & 400777 & 487 & $12.2(11.1-13.2)$ & $1.46(1.30-1.63)$ \\
\hline 2 & 132173 & 219 & $16.6(14.4-18.8)$ & $1.94(1.67-2.26)$ \\
\hline$\geq 3$ & 74436 & 196 & $26.3(22.6-30.0)$ & $3.04(2.59-3.57)$ \\
\hline \multicolumn{5}{|l|}{ Total no. of surgeries } \\
\hline 0 & 1426210 & 1179 & $8.3(7.8-8.7)$ & Referent \\
\hline 1 & 304774 & 343 & $11.3(10.1-12.4)$ & $1.36(1.20-1.54)$ \\
\hline 2 & 141129 & 204 & $14.5(12.5-16.4)$ & $1.66(1.42-1.94)$ \\
\hline$\geq 3$ & 161483 & 355 & $22.0(19.7-24.3)$ & $2.89(2.28-2.93)$ \\
\hline \multicolumn{5}{|c|}{ Type of anesthesia used for surgery } \\
\hline General & 515854 & 783 & $15.2(14.1-16.2)$ & $1.79(1.62-1.96)$ \\
\hline Local or regional only & 91532 & 119 & $13.0(10.7-15.3)$ & $1.52(1.24-1.85)$ \\
\hline No surgery & 1426210 & 1179 & $8.3(7.8-8.7)$ & Referent \\
\hline \multicolumn{5}{|l|}{ Age at first surgery, yr } \\
\hline$<15$ & 119267 & 262 & $22.0(19.3-24.6)$ & $2.50(2.14-2.91)$ \\
\hline $15-19$ & 128395 & 241 & $18.8(16.4-21.1)$ & $1.99(1.68-2.27)$ \\
\hline $20-24$ & 146884 & 212 & $14.4(12.5-16.4)$ & $1.69(1.45-1.97)$ \\
\hline$\geq 25$ & 212840 & 187 & $8.8(7.5-10.0)$ & $1.19(1.01-1.40)$ \\
\hline No surgery & 1426210 & 1179 & $8.3(7.8-8.7)$ & Referent \\
\hline \multicolumn{5}{|c|}{ Time between first surgery and future pregnancy, yr } \\
\hline$<5$ & 250388 & 268 & $10.7(9.4-12.0)$ & $1.25(1.09-1.44)$ \\
\hline $5-9$ & 151271 & 234 & $15.5(13.5-17.4)$ & $1.81(1.56-2.09)$ \\
\hline$\geq 10$ & 205727 & 400 & $19.4(17.5-21.3)$ & $2.53(2.23-2.87)$ \\
\hline No surgery & 1426210 & 1179 & $8.3(7.8-8.7)$ & Referent \\
\hline
\end{tabular}

have missed interventions performed without anesthesia for which opioid analgesics were prescribed. We could not verify that opioids were consumed through pharmacy or claims records; nor could we determine the type of opioid used, the cause of opioid use and whether women used prescription or illegal opioids. We could not confirm that neonatal abstinence syndrome was caused by opioids, but only a small fraction is attributed to other drugs. ${ }^{5,6}$ We had no information on the severity of neonatal abstinence syndrome in infants. The generalizability of our findings to regions with a different prevalence of opioid use disorders remains unclear.

\section{Conclusion}

This study suggests that prepregnancy surgery is associated with an increased risk of neonatal abstinence syndrome in future offspring. Prescription opioids for postsurgical pain control may lead to opioid use disorders problematic enough to persist in pregnancy and affect future offspring. Efforts to limit perioperative exposure to opioids and postoperative overprescribing in women should be further encouraged. Screening for opioid use disorders in pregnant women with a history of surgery may also help identify women who would benefit from opioid maintenance therapy earlier in pregnancy. 


\section{References}

1. Patrick SW, Schumacher RE, Benneyworth BD, et al. Neonatal abstinence syndrome and associated health care expenditures: United States, 2000-2009. JAMA 2012;307:1934-40.

2. Brown JD, Doshi PA, Pauly NJ, et al. Rates of neonatal abstinence syndrome amid efforts to combat the opioid abuse epidemic. JAMA Pediatr 2016;170: 1110-2.

3. Filteau J, Coo H, Dow K. Trends in incidence of neonatal abstinence syndrome in Canada and associated healthcare resource utilization. Drug Alcohol Depend 2018;185:313-21.

4. McQueen K, Murphy-Oikonen J. Neonatal abstinence syndrome. N Engl J Med 2016;375:2468-79.

5. Kocherlakota P. Neonatal abstinence syndrome. Pediatrics 2014;134:e547-61.

6. Hudak ML, Tan RC, Committee on Drugs; Committee on Fetus and Newborn; American Academy of Pediatrics. Neonatal drug withdrawal. Pediatrics 2012;129: e540-60.

7. Witt CE, Rudd KE, Bhatraju P, et al. Neonatal abstinence syndrome and early childhood morbidity and mortality in Washington state: a retrospective cohort study. J Perinatol 2017;37:1124-9.

8. Uebel H, Wright IM, Burns L, et al. Reasons for rehospitalization in children who had neonatal abstinence syndrome. Pediatrics 2015;136:e811-20.

9. Wunsch $\mathrm{H}$, Wijeysundera DN, Passarella MA, et al. Opioids prescribed after lowrisk surgical procedures in the United States, 2004-2012. JAMA 2016;315: 1654-7.

10. Neuman MD, Bateman BT, Wunsch H. Inappropriate opioid prescription after surgery. Lancet 2019;393:1547-57.

11. Harbaugh CM, Lee JS, Hu HM, et al. Persistent opioid use among pediatric patients after surgery. Pediatrics 2018;141:e20172439.

12. Brummett CM, Waljee JF, Goesling J, et al. New persistent opioid use after minor and major surgical procedures in US adults. JAMA Surg 2017;152:e170504.

13. Ministry of Health and Social Services. Med-Echo System Normative Framework - Maintenance and Use of Data for the Study of Hospital Clientele. Québec: Government of Quebec; 2017.

14. Chen CY, Storr CL, Anthony JC. Early-onset drug use and risk for drug dependence problems. Addict Behav 2009;34:319-22.

15. Miech R, Johnston L, O'Malley PM, et al. Prescription opioids in adolescence and future opioid misuse. Pediatrics 2015;136:e1169-77.

16. Colvin LA, Bull F, Hales TG. Perioperative opioid analgesia - when is enough too much? A review of opioid-induced tolerance and hyperalgesia. Lancet 2019;393: 1558-68.

17. Glare P, Aubrey KR, Myles PS. Transition from acute to chronic pain after surgery. Lancet 2019;393:1537-46.
18. Landry JS, Croitoru D, Menzies D. Validation of ICD-9 diagnostic codes for bronchopulmonary dysplasia in Quebec's provincial health care databases. Chronic Dis Inj Can 2012;33:47-52.

19. Tairou F, De Wals P, Bastide A. Validity of death and stillbirth certificates and hospital discharge summaries for the identification of neural tube defects in Quebec City. Chronic Dis Can 2006;27:120-4.

20. Seal KH, Shi Y, Cohen G, et al. Association of mental health disorders with prescription opioids and high-risk opioid use in US veterans of Iraq and Afghanistan. JAMA 2012;307:940-7.

21. Dupouy J, Lapeyre-Mestre M, Oustric S. Psychiatric disorders as predictors of longterm opioid therapy and the need for treating chronic pain correctly in patients with prior opioid substance use disorder: a commentary. Pain 2017;158:6-7.

22. Pampalon R, Hamel D, Gamache P, et al. Validation of a deprivation index for public health: a complex exercise illustrated by the Quebec index. Chronic Dis Inj Can 2014;34:12-22.

23. Spiegelman D, Hertzmark E. Easy SAS calculations for risk or prevalence ratios and differences. Am J Epidemiol 2005;162:199-200.

24. Liang KY, Zeger SL. Longitudinal data analysis using generalized linear models. Biometrika 1986;73:13-22.

25. Austin PC. An introduction to propensity score methods for reducing the effects of confounding in observational studies. Multivariate Behav Res 2011;46:399-424.

26. Clarke H, Soneji N, Ko DT, et al. Rates and risk factors for prolonged opioid use after major surgery: population-based cohort study. BMJ 2014;348:g1251.

27. Alam A, Gomes $\mathrm{T}$, Zheng $\mathrm{H}$, et al. Long-term analgesic use after low-risk surgery: a retrospective cohort study. Arch Intern Med 2012;172:425-30.

28. Sun EC, Darnall BD, Baker LC, et al. Incidence of and risk factors for chronic opioid use among opioid-naive patients in the postoperative period. JAMA Intern Med 2016;176:1286-93.

29. Brat GA, Agniel D, Beam A, et al. Postsurgical prescriptions for opioid naive patients and association with overdose and misuse: retrospective cohort study. BMJ 2018;360:j5790.

30. Apfelbaum JL, Chen C, Mehta SS, et al. Postoperative pain experience: results from a national survey suggest postoperative pain continues to be undermanaged. Anesth Analg 2003;97:534-40.

31. Cicero TJ, Ellis MS, Surratt HL, et al. The changing face of heroin use in the United States: a retrospective analysis of the past 50 years. JAMA Psychiatry 2014;71:821-6.

32. Lemon LS, Caritis SN, Venkataramanan R, et al. Methadone versus buprenorphine for opioid use dependence and risk of neonatal abstinence syndrome. Epidemiology 2018;29:261-8.

33. Vogel L. Opioid prescriptions still rising but for smaller quantities. CMAJ 2017;189:E1538.

34. Burns L, Mattick RP. Using population data to examine the prevalence and correlates of neonatal abstinence syndrome. Drug Alcohol Rev 2007;26:487-92.
Competing interests: Nathalie Auger reports receiving grants from the Canadian Institutes of Health Research and the Fonds de recherche du Québec - Santé during the conduct of the study. No other competing interests were declared.

This article has been peer reviewed.

Affiliations: University of Montreal Hospital Research Centre (Auger, Carrier, Ayoub), School of Public Health; Institut national de santé publique du Québec (Auger, Ayoub); Department of Psychiatry (Low), McGill University; Departments of Anesthesiology and Medicine (Carrier), Critical Care Division, University of Montreal Hospital; Department of Pediatrics (Luu), Sainte-Justine Hospital Research Centre, University of Montreal, Montréal, Que.

Contributors: Nathalie Auger and Aimina Ayoub conceived of and designed the study. Aimina Ayoub analyzed the data, with input from
Nathalie Auger and François Carrier. Nancy Low, François Carrier and Thuy Mai Luu helped interpret the results. Nathalie Auger and Aimina Ayoub drafted the manuscript, and Nancy Low, François Carrier and Thuy Mai Luu critically revised it for important intellectual content. All authors gave final approval of the version to be published and agreed to be accountable for all aspects of the work.

Funding: This study was funded by the Canadian Institutes of Health Research (PJT-156062) and the Fonds de recherche du Québec-Santé (34695).

Data sharing: The data used in this study can be obtained from the Ministry of Health and Social Services of Quebec following standard access procedures.

Accepted: May 29, 2019

Correspondence to: Nathalie Auger, nathalie.auger@inspq.qc.ca 